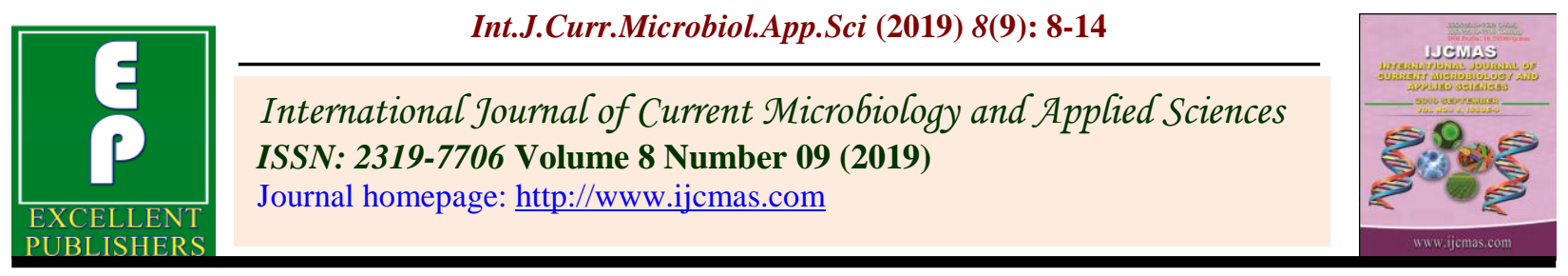

Original Research Article

https://doi.org/10.20546/ijcmas.2019.809.002

\title{
Functional Status among Rural and Urban Elderly in Ranebennur Taluk, Haveri District, Karnataka, India
}

\author{
Aishwarya Koppad* and Vinutha U. Muktamath \\ Department of Human Development and Family Studies College of Community Science \\ University of Agricultural Sciences, Dharwad-580005, Karnataka, India
}

*Corresponding author

\section{A B S T R A C T}

\section{Keywords}

Elderly, Functional status, Activities of daily living, Instrumental activities of daily living, Locality

Article Info

Accepted:

04 August 2019

Available Online:

10 September 2019
The present study aimed to assess the functional status among 180 rural and urban elderly aged 60 and above during 2018-2019 in Ranebennur Taluk of Haveri district of Karnataka. A self-structured schedule was used to collect the general information, functional status was measured by using Katz Index of Independence in Activities of Daily Living (ADL) and Lawton Instrumental Activities of Daily Living (IADL). The results showed that with regard to ADL, 41.67 per cent of males functioned fully and only 0.55 per cent had severe impairment, while 53.33 per cent of females functioned fully, 2.78 per cent had moderate impairment and 1.67 per cent had severe impairment. Regarding IADL, 16.11 per cent and 26.11 per cent of the male elderly had low and high level of functioning respectively. Among female elderly 23.89 per cent and 33.89 per cent exhibited low and high level of functioning respectively. Majority of the rural (96.66\%) and urban elderly $(93.33 \%)$ belonged to full function category. However, no significant association and difference between locality and ADL was observed. In rural (67.78\%) and urban (52.22\%) area most of the respondents belonged to high category of IADL and a significant association between IADL and locality was found.

\section{Introduction}

India is a land of most rapidly aging population (aged 60 and above) in the developing world. This is due to the combination of declining birth rates and increasing life expectancy. Indian elderly population accounted for 8.60 per cent in 2011 census and is projected to rise to 11.10 per cent by 2025 (Mahajan and Ray, 2013). The huge elderly population in India require multidimensional support and one of the major determinants of the quality of life of elderly subjects is their functional status. Functional status is the individual's ability to live independently and relate to his/her environment or perform normal daily activities for basic needs and carry out normal functions to maintain health and well- being. According to Knight (2000) functional status has been used to describe motor function, ability to perform activities of daily living (ADL) and the ability to perform instrumental activities of daily living (IADL). The human aging is dynamic and progressive, triggering decline in functional capacity of the elderly. 
Activities of daily living refers to a range of common activities whose performance is required for personal self-maintenance and independent community residence like bathing, dressing, toileting, transferring, continence and feeding.

Instrumental activities of daily living is concerned with more complex activities needed for independent living in a person's immediate environment. This type of activities measure competence in functions that are less bodily oriented than physical self-maintenance like using telephone, shopping, food preparation, housekeeping, laundry, mode of transportation, responsibility for own medications and ability to handle finance (Dolai and Chakrabarty, 2013).

Thus, decline in functional status is measured by an individual's loss of independence in activities of daily living and instrumental activities of daily living. Threat to functional independence in elderly arises as a result of physiological changes from the ageing process. Functional status is considered, as the basis of an efficient geriatric assessment, giving a broad and interdisciplinary approach to health status. The decline in functional status may also be associated with a number of multidimensional factors like biological or physiological impairment, nutrition, mood, health status, social relationships, physical environment and the demographic, socioeconomic, cultural and psychological conditions. It is also likely to be influenced by health perceptions. These factors determine functional status in older adults.

The elderly population is likely to suffer from health problems and irreversible decline in functional abilities. Hypertension, diabetes, heart attack, stroke, arthritis, cataract etc. are the major health problems of older adults. It also includes changes such as reduced muscle strength, bone density, bladder capacity and pulmonary ventilation. Functional limitation increases dependency on others for support. Loss of functional status is associated with increased risk of institutionalization, stay at home, hospitalization, need for caregiver and falls among elderly and is considered as independent risk factor for mortality (Dolai and Chakrabarty, 2013). Considering these facts, the present study was carried out with an objective to assess the functional status (activities of daily living and instrumental activities of daily living) of elderly in urban and rural areas of Ranebennur Taluk.

\section{Materials and Methods}

\section{Research design}

Differential design was used to compare the functional status among rural and urban elderly group.

\section{Locale}

The present research study was carried out exclusively in Ranebennur Taluk of Haveri district of Karnataka state, India. The city area and two villages were selected for the study.

\section{Population}

The group of elderly from Ranebennur city and selected villages of Ranebennur Taluka aged 60 and above formed the population of study.

\section{Sample}

The sample of the study included 180 elderly (90 from urban and 90 from rural) who were selected by snow ball technique of sampling.

\section{Research tools}

The self-structured general information schedule was used to collect information about 
respondents age, gender, locality, religion, education, type of family, marital status, living arrangement, working status and health problems.

Daily living activities of elderly was assessed by using Katz Index of Independence in Activities of Daily Living (ADL) by Katz et al., (1963). The scale consisted of 6 activities with 2 statements in each activity. Each activity has to be answered as 'independence' and 'dependence' with a score of ' 1 ' and ' 0 ' respectively. The scale includes activities like bathing, dressing, toileting, transferring, continence, and feeding. The score ranges from 0-6 and is classified into full function (56), moderate impairment (3-4) and severe functional impairment (0-2).

The independent living skills of elderly was assessed by using the Lawton Instrumental Activities of Daily Living (IADL) scale by Lawton and Brody (1969). It contains 8 categories with 3 to 5 statements in each category. Each statement has to be answered as 'yes' or 'no' with a score of ' 1 ' and ' 0 ' respectively. The items such as ability to use telephone, shopping, food preparation, housekeeping, laundry, mode of transportation, responsibility for own medications and ability to handle finance. The maximum score is 8 and minimum is 0 and the scores are classified as high (5-8) and low function (0-4).

A pilot study was conducted to test the reliability of the tools. The reliability for Katz index of independence in activities of daily living was found to be 0.87 and for Lawton instrumental activities of daily living scale was 0.86 .

Socio Economic Status (SES) was measured by Aggarwal et al., (2005) scale and the data was computed by IBM SPSS Statistics version 21 software.
The anthropometric measurements of the respondents were taken by the researcher. The anthropometric rod to measure height, and standard weighing machine to assess weight was used. A single measuring tape was used to assess the mid upper arm circumference and calf circumference.

\section{Data collection}

A household survey was conducted and data collection tools were administered individually. The elderly were briefed about the purpose of the study and oral consent was obtained to conduct the study. The caregiver's opinion was also sought in cases wherever available in order to substantiate the responses given by the elderly, especially for physical functioning. It took about 30-40 minutes to collect the data from each sample.

\section{Results and Discussion}

The demographic characteristics of the sample selected for the study is presented in the Table 1. In rural area 68.90 per cent belonged to 'young old', 20 per cent were 'old old' and 11.10 per cent were in 'oldest old' category. The same trend was observed in urban area. Totally, 76.11 per cent were 'young old', 17.22 per cent 'old old' and 6.67 per cent belonged to 'oldest old' category.

With regard to gender 43.30 per cent were males and 56.70 per cent females from rural area, whereas 41.10 per cent were males and 58.90 per cent were females in urban area.

Majority of the rural $(94.40 \%)$ and urban (96.70 \%) subjects were Hindus and only few were Muslims.

In rural area 47.78 per cent were illiterates, 41.11 per cent completed higher primary, 10 per cent PUC and only 1.11 per cent were graduates. In urban area 41.11 per cent were 
illiterates, 25.56 per cent completed higher primary, 8.89 per cent completed PUC and 24.44 per cent were graduates.

Regarding family type, in rural sample majority of the respondents $(64.40 \%)$ were from joint family while in urban area most of them were from nuclear family $(53.30 \%)$ system. Majority of the rural $(57.78 \%)$ and urban $(67.78 \%)$ elderly were married.

With respect to living arrangement majority of the subjects $(51.10 \%)$ were living with spouse and children followed by living with children $(33.30 \%)$, living alone $(7.80 \%)$, living with spouse $(5.60 \%)$ and only few were living with others or relatives $(2.20 \%)$. The same trend was observed in urban sample.

In rural area most of them (55.60\%) were currently working, while majority of urban subjects were non-working (61.10\%). With regard to socioeconomic status, majority of the rural $(65.60 \%)$ and urban $(53.33 \%)$ families belonged to lower middle class followed by upper middle (24.40\% Vs 38.89 $\%)$ and poor category (10.00\% Vs $7.78 \%)$. Most of the rural (63.33\%) and urban (72.22 $\%)$ subjects reported 1 to 2 health problems (hypertension and diabetes).

Table 2 presents that gender wise distribution of elderly based on their functional status. With regard to activities of daily living, 41.67 per cent of males fully functioned and only 0.55 per cent had severe impairment, while 53.33 per cent of females fully functioned, 2.78 per cent had moderate impairment and 1.67 per cent had severe impairment. Totally 95 per cent fully functioned, 2.78 per cent had moderate impairment and 2.22 per cent had severe level of impairment.

Table.1 Demographic characteristics of the respondents

\begin{tabular}{|c|c|c|c|c|}
\hline Characteristics & Category & Rural (n=90) & Urban $(n=90)$ & Total \\
\hline \multirow{3}{*}{ Age } & Young old (60-74 years) & $62(68.90)$ & $75(83.33)$ & $137(76.11)$ \\
\hline & Old old (75-84 years) & $18(20.00)$ & $13(14.44)$ & $31(17.22)$ \\
\hline & Oldest old ( $\geq 85$ years) & $10(11.10)$ & $2(2.23)$ & $12(6.67)$ \\
\hline \multirow[t]{2}{*}{ Gender } & Male & $39(43.30)$ & $37(41.10)$ & $76(42.22)$ \\
\hline & Female & $51(56.70)$ & $53(58.90)$ & $104(57.78)$ \\
\hline \multirow[t]{2}{*}{ Religion } & Hindu & $85(94.40)$ & $87(96.70)$ & $172(95.55)$ \\
\hline & Muslim & $5(5.60)$ & $3(3.30)$ & $8(4.45)$ \\
\hline \multirow{4}{*}{ Education } & Illiterate & $43(47.78)$ & $37(41.11)$ & $80(44.45)$ \\
\hline & Higher primary & $37(41.11))$ & $23(25.56)$ & $60(33.33)$ \\
\hline & PUC & $9(10.00)$ & $8(8.89)$ & $17(9.44)$ \\
\hline & Graduation and above & $1(1.11)$ & $22(24.44)$ & $23(12.78)$ \\
\hline \multirow[t]{2}{*}{ Type of family } & Nuclear & $32(35.60)$ & $48(53.30)$ & $80(44.44)$ \\
\hline & Joint & $58(64.40)$ & $42(46.70)$ & $100(55.56)$ \\
\hline \multirow[t]{2}{*}{ Marital status } & Married & $52(57.78)$ & $61(67.78)$ & $113(62.78)$ \\
\hline & Widow/ widower & $38(42.22)$ & $29(32.22)$ & $67(37.22)$ \\
\hline \multirow{5}{*}{ Living arrangement } & With spouse and children & $46(51.10)$ & $44(48.90)$ & $90(50.00)$ \\
\hline & Only with spouse & $5(5.60)$ & $17(18.90)$ & $22(12.22)$ \\
\hline & Only with children & $30(33.30)$ & $20(22.20)$ & $50(27.78)$ \\
\hline & Alone & $7(7.80)$ & $5(5.60)$ & $12(6.67)$ \\
\hline & Others/ Relatives & $2(2.20)$ & $4(4.40)$ & $6(3.33)$ \\
\hline \multirow[t]{2}{*}{ Working status } & Working & $50(55.60)$ & $35(38.90)$ & $85(47.22)$ \\
\hline & Non-working & $40(44.40)$ & $55(61.10)$ & $95(52.78)$ \\
\hline \multirow[t]{3}{*}{ Socio-Economic Status } & Upper middle (46-60) & $22(24.40)$ & $35(38.89)$ & $57(31.67)$ \\
\hline & Lower middle (31-45) & $59(65.60)$ & $48(53.33)$ & $107(59.44)$ \\
\hline & Poor (16-30) & $9(10.00)$ & $7(7.78)$ & $16(8.89)$ \\
\hline \multirow{3}{*}{$\begin{array}{c}\text { Number of health } \\
\text { problems }\end{array}$} & No health problems & $20(22.22)$ & $11(12.22)$ & $31(17.22)$ \\
\hline & $1-2$ & $57(63.33)$ & $65(72.22)$ & $122(67.78)$ \\
\hline & $3-4$ & $13(14.45)$ & $14(15.56)$ & $27(15.00)$ \\
\hline
\end{tabular}

Figures in parenthesis indicate percentages 
Table.2 Gender wise distribution of elderly based on their functional status

\begin{tabular}{|c|c|c|c|c|}
\hline \multirow{2}{*}{$\begin{array}{l}\text { Functional } \\
\text { status }\end{array}$} & \multirow[t]{2}{*}{ Category } & \multicolumn{3}{|c|}{ Gender } \\
\hline & & Male & Female & Total \\
\hline \multirow{4}{*}{$\begin{array}{l}\text { Activities of } \\
\text { daily living }\end{array}$} & Full function & $75(41.67)$ & $96(53.33)$ & $171(95.00)$ \\
\hline & Moderate impairment & - & $5(2.78)$ & $5(2.78)$ \\
\hline & Severe impairment & $1(0.55)$ & $3(1.67)$ & $4(2.22)$ \\
\hline & Total & $76(42.22)$ & $104(57.78)$ & $180(100)$ \\
\hline \multirow{3}{*}{$\begin{array}{ll}\text { Instrumental } & \\
\text { activities } & \text { of } \\
\text { daily living } & \end{array}$} & Low (Dependent) & $29(16.11)$ & $43(23.89)$ & $72(40.00)$ \\
\hline & High (Independent) & $47(26.11)$ & $61(33.89)$ & $108(60.00)$ \\
\hline & Total & $76(42.22)$ & $104(57.78)$ & $180(100)$ \\
\hline
\end{tabular}

Figures in parenthesis indicate percentages

Table.3a Influence of locality on activities of daily living among rural and urban elderly

\begin{tabular}{|c|c|c|c|c|c|c|c|}
\hline \multirow{2}{*}{ Locality } & \multicolumn{9}{|c|}{ Levels of activities of daily living } & Modified & Mean \pm SD & t-value \\
\cline { 2 - 6 } & $\begin{array}{c}\text { Full } \\
\text { function }\end{array}$ & $\begin{array}{c}\text { Moderate } \\
\text { impairment }\end{array}$ & $\begin{array}{c}\text { Severe } \\
\text { impairment }\end{array}$ & Total & $\chi^{\mathbf{2}}$ & & \\
\hline Rural & 87 & 1 & 2 & 90 & $1.85^{\mathrm{NS}}$ & $5.83 \pm 0.93$ & \multirow{2}{*}{$0.66^{\mathrm{NS}}$} \\
& $(96.70)$ & $(1.10)$ & $(2.20)$ & $(100)$ & & & \\
\hline Urban & 84 & 4 & 2 & 90 & & $5.74 \pm 0.85$ & \\
& $(93.33)$ & $(4.44)$ & $(2.23)$ & $(100)$ & & & \\
\cline { 1 - 5 } Total & $\mathbf{1 7 1}$ & $\mathbf{5}$ & $\mathbf{4}$ & $\mathbf{1 8 0}$ & & $\mathbf{5 . 7 8} \pm \mathbf{0 . 8 9}$ & \\
& $\mathbf{( 9 5 . 0 0 )}$ & $\mathbf{( 2 . 7 8 )}$ & $\mathbf{( 2 . 2 2 )}$ & $\mathbf{( 1 0 0 )}$ & & & \\
\hline
\end{tabular}

Figures in parentheses indicate percentage

NS- Non-Significant

Table.3b Influence of locality on instrumental activities of daily living among rural and urban elderly

\begin{tabular}{|c|c|c|c|c|c|c|}
\hline \multirow{2}{*}{ Locality } & \multicolumn{1}{|c|}{ Levels of instrumental activities of daily living } & \multirow{2}{*}{$\chi^{\mathbf{2}}$} & Mean \pm SD & t-value \\
\cline { 2 - 4 } & Low & High & Total & & & \\
\hline Rural & $29(32.20)$ & $61(67.80)$ & $90(100)$ & $4.53^{*}$ & $4.95 \pm 2.08$ & $0.45^{\mathrm{NS}}$ \\
\hline Urban & $43(47.80)$ & $47(52.20)$ & $90(100)$ & & $4.81 \pm 2.14$ & \\
\hline Total & $\mathbf{7 2 ( 4 0 . 0 0 )}$ & $\mathbf{1 0 8 ( 6 0 . 0 0 )}$ & $\mathbf{1 8 0 ( 1 0 0 )}$ & & $\mathbf{4 . 8 8} \pm \mathbf{2 . 1 1}$ & \\
\hline
\end{tabular}

Figures in parentheses indicate percentage

* Significant at 5 per cent level

NS- Non Significant

Regarding instrumental activities of daily living 16.11 per cent and 26.11 per cent of the male subjects had low and high level of functioning respectively. The 23.89 per cent and 33.89 per cent of female subjects exhibited low and high level of functioning. With respect to total respondents most of the respondents $(60.00 \%)$ revealed high level of functioning, followed by low level of functioning $(40.00 \%)$.

Table 3a indicates the influence of locality on activities of daily living of rural and urban elders. In rural, majority of the respondents 
(96.66 \%) belonged to full function category followed by severe impairment $(2.23 \%)$ and moderate impairment $(1.11 \%)$. With regard to urban elderly, majority of the respondents functioned fully $(93.33 \%)$ followed by moderately impaired (4.44\%) and severely impaired $(2.23 \%)$. However, no significant association and difference between locality and activities of daily living was observed.

Influence of locality on instrumental activities of daily living is presented in Table $3 \mathrm{~b}$. In rural area most of the respondents belonged to high category $(67.78 \%)$ and 32.22 per cent in low category. The same trend was observed in urban area. The $\chi^{2}$ value revealed significant association between locality and instrumental activities of daily living. However, statistical analysis revealed no significant difference between locality and instrumental activities of daily living.

The present study revealed (Table 2) that majority of male and female elderly were functioning fully $(95.00 \%)$ and only few were moderately and severely impaired in activities of daily living (ADL). The reason may be that, the daily activities are fundamental for functioning independently in life. Hence, these activities are normally performed by an individual. These scores were high in young old elderly in comparison to the old ones. In the study, only few samples were affected by severe health problems like stroke, arthritis, severe joint pain, cataract and kidney problem that lead to dependence in ADL.

The most of the male and female elderly $(60.00 \%)$ were highly functioning in instrumental activities of daily living (IADL) and other were low functioning. The low functioning in instrumental activities may be because, these activities are not essential for fundamental functioning; they are more complex, require a higher level of personal autonomy and greater interaction with the environment. The reason may be that women more independent than men in activities such as laundry, housekeeping and cooking, whereas men better in managing traveling and financial matters independently. These findings are in line with the study conducted by Inocian et al., (2014) which indicated that community dwelling elderly could independently perform all ADL and IADL activities. Health related condition was significant and negatively correlated with ADL among community elderly in Philippines. Lazaro-Alquezar et al., (2007) also quoted same reason that traditionally women have been more bounded to domestic work, while men have been bounded to the administration of money.

The results of the present study indicated that (Table 3a and Table 3b) that locality did not impact on ADL, but significant association was observed in IADL functioning. Rural elderly exhibited high functioning in IADL. It may be due to the factor that IADL activities are more complex than the ADL activities which requires only good physical strength. Also the prevalence of health problems and non-working condition was high in urban sample. They spent time with reading, sitting, watching TV and sleeping longer hours. Rural elderly were physically active and they were doing shopping, laundry and food preparation agriculture work etc. This was line with Wang et al., (2009) who reported that those who lived in rural areas of China had the highest likelihood of maintaining independence in functional performance than urban elderly.

So, the family should give more encouragement to the elderly to come out of the house and participate in social activities. Elderly having musculoskeletal problems should be provided with rehabilitative support in the community settings. Cities and rural areas should be made age-friendly like 
railings for support in foot path, non-slippery floor, etc. Geriatric friendly transport services like low floor buses will help in accommodating their functional decline.

\section{Acknowledgement}

The research paper is a part of masteral research conducted under the aegis of University of Agricultural Sciences, Dharwad. So, I acknowledge University of Agricultural Sciences, Dharwad for the support and rural and urban elderly from Ranebennur Taluk, Haveri district, Karnataka.

\section{References}

Aggarwal, O. P., Bhasin, S. K., Sharma, A. K., Chhabra, P., Aggarwal, K., and Rajoura, O. P. 2005. A new instrument (scale) for measuring the socioeconomic status of a family: Preliminary study. Indian J. Comm. Med. 34 (4): 111-114.

Dolai, M. C., and Chakrabarty, F. 2013. Functional status of the elderly Santal people. Int. J. Humanities and Soc. Sci. Invention. 2 (1): 1-6.

Inocian, E. P., Inocian, E. P., and Ysatam, E. I. 2014. The dependency needs in the activities of daily living performance among Filipino elderly. Int. Res. J. Med. Med. Sci. 2 (2): 44-50.
Katz, S., Ford, A. B., Moskowitz, R. W., Jackson, B. A., and Jaffe, M. W. 1963. Studies of illness in the aged: The index of ADL: A standardized measure of biological and psychosocial function. Int. J. Am. Med. Assoc. 185 (12): 914919.

Knight, M. M., 2000. Cognitive ability and functional status. J. Advanced Nursing. 31 (6): 1459-1469.

Lawton, M. P., and Brody, E. M. 1969. Assessment of older people: Selfmaintaining and instrumental activities of daily living. The Gerontologist. 9 (3): 179-186.

Lazaro-Alquezar, A., Rubio Aranda, E., Sanchez Sanchez, A., and Garcia Herrero, J. C. 2007. Functional capacity for daily living activities among senior citizens attending community centers in the city of Zaragoza, Spain. Rev. Esp. Salud. Publica. 81: 625-636.

Mahajan, A., and Ray, A. 2013. The Indian elder: Factors affecting geriatric care in India. Glob. J. Med. Public Health. 2: 15.

Wang, D., Zheng, J., Kurosawa, M., Inaba, Y., and Kato, N. 2009. Changes in activities of daily living (ADL) among elderly Chinese by marital status, living arrangement and availability of health care over a 3-year period. Environ. Health Prev. Med. 14 (1): 128-141.

\section{How to cite this article:}

Aishwarya Koppad and Vinutha U. Muktamath. 2019. Functional Status among Rural and Urban Elderly in Ranebennur Taluk, Haveri District, Karnataka, India. Int.J.Curr.Microbiol.App.Sci. 8(09): 8-14. doi: https://doi.org/10.20546/ijcmas.2019.809.002 